Acta Poetica 29-1

PRIMAVERA

2008

\title{
La cultura popular como fuente. Procesos de inocultamiento en obras literarias y artísticas mexicanas del siglo $\mathrm{XX}$
}

\author{
Patrice Giasson
}

Basándose en algunos ejemplos concretos, y partiendo de la idea de inocultamiento evocada por Carlos Monsiváis al hablar del arte de la Revolución mexicana, este artículo reflexiona sobre el legado dejado por la cultura popular a los artistas y escritores mexicanos del siglo xx. De manera general, dicho legado se caracterizaría por el desarrollo de un espíritu crítico en numerosas obras posrevolucionarias, por la expansión de lo satírico y, de manera similar al arte carnavalesco, por la función que llega a ocupar la risa en el reajuste de las anomalías sociales.

Through different concrete examples, and based on the idea of "inocultamiento" ("the impossibility of hiding") evoked by Carlos Monsiváis as he speaks of Mexican Revolution art, this article evaluates the inheritance left by popular culture on xxth century Mexican artists and writers. This inheritance would be mainly characterized by the development of a critical consciousness in different post-revolutionaries creations, by the expansion of the satire and, in a similar way of carnival art forms, by the function that gets to occupy laugh in the readjustment of social anomalies.

Palabras clave: cultura popular, inocultamiento, arte, Revolución mexicana, risa 

Acta Poetica 29-1

PRIMAVERA

2008

Patrice Giasson

\section{La cultura popular como fuente. Procesos de inocultamiento en obras literarias $\mathrm{y}$ artísticas mexicanas del siglo $\mathrm{xx}$}

A principios de 1910, como lo recuerda Armando de Maria y Campos en su ensayo El teatro de género chico en la Revolución mexicana, irrumpe en la escena mexicana una obra teatral profundamente irónica y cómica titulada México Nuevo, que deja entrever que la Revolución está a punto de estallar. Por medio de la aparición de San Expedito, enviado a la tierra para investigar sobre la situación política en México, son invocadas las personalidades políticas del momento. En un cuarto de hotel, San Expedito lee en voz alta los nombres escritos en los anuncios de un periódico. A medida que son leídos sus nombres, los personajes van apareciendo:

DiRECTOR: Mi circo, señor, tiene números notables, los cuales pueden compararse con la política. Por ejemplo; los políticos son los trapecios volantes, lo mismo vuelan para un lado que para el otro... Los diputados son los perros amaestrados...

SAN EXPEDITO: ¿Y los senadores?

DIRECTOR: Pues los senadores... cenan y comen del presupuesto.

SAN EXPEDITO: ¿Y qué otros artistas tiene usted? 
DiRECTOR: Tengo también un magnífico número de hombres forzudos, que levantan pesas y pesos; los que levantan las pesas son hércules y los que levantan los pesos son los "científicos".

SAN EXPEDITO: ¿Eso es todo?

DIRECTOR: No, señor, tengo otro numerito maravilloso, imponente; un ayunador como no hay otro: ¡el pueblo!

SAN EXPEDITO: ¿Y los payasos?

DiRECTOR: Los más notables son $\mathrm{X}$ y Z (aquí los nombres de dos diputados desaparecidos, cuyos nombres guardamos por respeto [nota de Maria y Campos])

SAN EXPEDITO: ¿Y hacen reír a la gente?

DiRECTOR: A carcajada. Todos ríen de ellos... (Maria y Campos, 52-53).

La repentina aparición de San Expedito parece efectivamente anunciar la inminencia de una revuelta general. No cabe duda de que el autor de la obra eligió voluntariamente a dicho santo para crear una situación cómica y reflexionar sobre "las cosas en curso en México" y la urgencia de arreglarlas lo más pronto posible. Las virtudes asociadas con San Expedito consisten, de hecho, en atender los casos urgentes, los casos que, de existir demora, causarían grandes perjuicios. Por otro lado, el hecho de que San Expedito aparezca en un lugar tan ordinario como un cuarto de hotel constituye una recuperación totalmente irónica de la larga tradición de "apariciones" en el culto católico de México. La novedad consiste precisamente en que la aparición divina de San Expedito no sirve para promulgar la fe entre los hombres, sino para hacer de Dios un testigo de los asuntos terrenales. El periódico - arma política por excelencia - es el nuevo medio sagrado que hace posible la "aparición" de los personajes, así como un divino pretexto para levantar el velo sobre la realidad oculta de la política interna. La gran carcajada de la gente hacia lo que ven sobre el escenario constituye de alguna manera un ejemplo del nacimiento de un auténtico espíritu de liberación popular característico del cam- 
bio radical que se está emprendiendo en las esferas de las artes y de las letras.

El juego de apariciones en México Nuevo se inscribe perfectamente en la definición que da Carlos Monsiváis del largo y gradual proceso de inocultamiento de sujetos populares durante la Revolución:

De golpe se derrumba la pretensión de una sociedad de respetos y ceremonias, cuyo punto de partida es la invisibilización de la mayoría [...]. Lo fundamental de la cultura popular de este período [1910-1920] es su capacidad para (por unos años) volver inocultables a los campesinos, a caballo o colgados en los postes o fusilados o a punto de invadir las ciudades [...] (Monsiváis, 149).

Se trata de un proceso de inocultamiento del cuerpo, del hablar, del pensar y del humor de la mayoría en el arte popular. Según Monsiváis, la Revolución había permitido también la aparición de temas prohibidos hasta entonces, como las obscenidades y el sexo: "Con el ánimo fornicador y pantagruélico que Mijaíl Bajtín halló en la Edad Media y el Renacimiento, irrumpe - verbaliza - la 'mitad inferior' del cuerpo, el 'abajo’ humano aparece” (Monsiváis, 159).

Pero, como veremos aquí, el espíritu de liberación que surge con la Revolución tuvo también como consecuencia influir profundamente y de manera duradera sobre el proceso de creación artística en las esferas cultas de México. No sólo en el universo de las artes plásticas - y de manera evidente en la pintura mural - , sino también en el campo literario, al trasformar para siempre la manera de escribir. Desde muchas perspectivas y de manera similar al Renacimiento europeo, el "renacimiento mexicano" de la primera mitad del siglo XX corresponde efectivamente a un período de emancipación, de

\footnotetext{
${ }^{1}$ En Giasson 2005, ya hemos tratado esta cuestión.
} 
liberación frente a las viejas escuelas, un período estimulado por una nueva ola de pensamiento, más cercano a la vida humana, a la naturaleza; ${ }^{2}$ a fin de cuentas, un período que permitió el nacimiento de un arte nuevo para un público cada vez más amplio. No en vano, al afirmar que los períodos históricos marcados por luchas sociales habían estimulado a artistas de gran calidad, Diego Rivera mencionaba en primer lugar a tres grandes renacentistas: Giotto y Orcagna en Italia, Brueghel en Flandes. ${ }^{3}$

\section{La risa liberadora}

De manera general, la Revolución es recordada como un período profundamente trágico. Pero basta consultar algunas obras de arte popular para darse cuenta de que en muchas de ellas no estaba ausente cierto grado de humor. Poco se ha dicho, por ejemplo, de la tonalidad burlesca que caracteriza algunas canciones populares conocidas como corridos mexicanos. Algunos historiadores de la música supieron demostrar cómo el corridista alcanza durante la Revolución una función clave como vocero y noticiero que recuerda la figura del juglar medieval; ${ }^{4}$ pero el análisis detallado de algunas canciones nos

\footnotetext{
${ }^{2}$ Panofsky recuerda que, con la pintura del Renacimiento, el interés por las formas clásicas, que califica de "regreso a las fuentes", acaba por armonizarse con un deseo de "regreso a la naturaleza", por lo que la escala humana se convierte en norma hasta en la representación de los héroes. "La interacción de ambos temas - añade - ocupa una función decisiva en el pensamiento humanista, no sólo en lo que se refiere a la relación entre las artes visuales y la literatura, sino también, poco tiempo después, en cuanto a la relación entre las artes visuales mismas [arquitectura, escultura y pintura]" (Panofsky, p. 33; la traducción es mía).

3 "Puede observarse que, en los períodos históricos en que una clase o un bloque de clases lucha contra la opresión social de otra clase dominadora, se suman a los insurrectos algunos artistas cuya cualidad estética aumenta hasta el nivel superior posible en su época: Giotto y Orcagna en Italia, Brueghel en Flandes, Chardin y Daumier en Francia" (Rivera, sección II, I).

${ }^{4}$ Cf., por ejemplo, Giménez 1991, y Mendoza 1990. En este último trabajo, Mendoza se desprende de la tradicional interpretación hispanófila del corrido para
} 
revela también que el corridista revolucionario no se limitaba a informar, sino que, a la manera del grabador revolucionario que animaba las hojas volantes, sabía recurrir a la sátira. Vicente Mendoza recuerda, por ejemplo, lo que ocurre después del golpe de Estado huertista:

De muy diversas maneras el pueblo de México manifestaba su aversión al presidente usurpador Victoriano Huerta. Los cancioneros populares lo zaherían, aprovechando todas las oportunidades y así se oía por las calles por lo menos el tonillo de un coro de ópera silbado por la plebe: "Deja la silla, mono de cuero, deja la silla sin dilación..." (Mendoza, 86).

Otro corrido, elaborado después de la firma de la Constitución de 1917, evoca con el mismo tono burlesco la falta de credibilidad de los dirigentes trasformados en acróbatas y personajes de circo, al igual que en la obra México Nuevo que vimos arriba:

Ya Venustiano Carranza tiene su Constituyente pa' enderezarle las leyes que les va a dar a la gente, Andale, chata, y nos vamos, ponte tus choclos morados; vamos al tiatro [sic] "Iturbide", verás a los Diputados, que hablan, se insultan y gritan; bajan y suben pa'riba y el que traga más pinole es quien tiene más saliva [...]

(Mendoza, 102).

Pero donde se nota más la función de lo satírico es en el teatro chico. Al abandonar el viejo estilo de las zarzuelas castellanas por la gruesa risa popular que acompaña a la Revolución, el teatro popular de principios de siglo adquiere una tonalidad propiamente mexicana no ausente de espíritu crítico:

reconocer la originalidad alcanzada por la "canción de gesta revolucionaria", que permitiría el desarrollo de una "literatura auténticamente mexicana" (149). 
Se trata de la irrupción en el escenario de la comedia, de los tipos populares con habla desgarrada, sus desplantes, su cursilería, su sal, el imperativo de las costumbres y las actitudes castizas, pero sobre todo la gracia, rara vez fina, deliberadamente gruesa y entre más, más eficaz, con que se manifiesta entre exabruptos, el descontento popular (Tavira, XIII).

Indudablemente, no podemos olvidar la herencia dejada por el arte popular de principios del siglo Xx en personajes como Cantinflas. Con Cantinflas, recuerda Luis de Tavira,

la carpa mexicana se cobra venganza sobre la paralizante dependencia lingüística y teatral que padeció el teatro mexicano frente a la decadencia del teatro español [y añade:] El triunfo de Cantinflas consistió en que no pretendió imitar el habla de los elocuentes, sino la frustración verbal del analfabeto (Tavira, XVI).

Verdadero hijo de la Revolución — nace en 1911 - Cantinflas simboliza, a través de sus películas, la libre expresión democrática y las aspiraciones colectivas de justicia social.

No cabe duda de que, por su carácter liberador y curativo, la risa llega a ocupar una función capital durante la Revolución. Henri Bergson fue seguramente uno de los primeros investigadores en describir con claridad el rol clave que puede jugar la risa en el reajuste de las anomalías sociales (Bergson, 130140). Dicha función "correctiva" fue también identificada por Bajtín en el arte popular medieval y posteriormente en la literatura renacentista. Al hablar, por ejemplo, del Quijote, el filósofo ruso veía en la redonda panza y en el "grotesco realismo" de Sancho una respuesta y un contrapeso al idealismo aislado, abstracto e insensible de su amo Don Quijote (Bakhtine, 31). El famoso personaje conocido como la Catrina, creado por el grabador José Guadalupe Posada al alba de la Revolución Mexicana, va también en este sentido. Si el grabador reviste la 
Catrina de manera tan excéntrica como las grandes damas de México, cuyas miradas están más dirigidas hacia la moda parisina que a la realidad mexicana, es justo para parodiar la vanidad de la alta sociedad. De manera general, la Catrina se burla también de cualquier tipo de vanidad. Como recuerda Bergson, "el remedio específico de la vanidad es la risa, y [...] el defecto esencialmente risible es la vanidad" (Bergson, 133). ${ }^{5}$

Las numerosas fotografías del mismo Pancho Villa parecen también encarnar esta venganza de la cultura popular. Y los primeros camarógrafos de la Mutual Film Company, ${ }^{6}$ que acompañaban a los soldados revolucionarios, supieron, sin duda, sacar provecho de la maciza contextura de Villa, de su viril figura de jinete y mujeriego, así como de su permanente sonrisa - que lleva hasta en las horas más duras de las campañas militares - , para crear alrededor de él un mito de invencibilidad, capaz de aterrorizar a la mayoría de sus enemigos.

Dichos ejemplos recuerdan en definitiva la existencia, en las obras revolucionarias, de un innegable lazo entre lo trágico y lo burlesco, lo serio y lo lúdico, la muerte y la vida.

\section{De abajo hacia arriba}

No cabe duda de que la Revolución Mexicana permitió el tránsito del savoir-faire y de las formas iconográficas provenientes de la cultura popular hacia el registro de la cultura oficial. Por ejemplo, Adolfo Best Maugard, en busca de una autenticidad estética mexicana, desarrolló una técnica de dibujo basada en los motivos más recurrentes del arte popular mexicano, técnica que será posteriormente enseñada en la mayoría de las escuelas. ${ }^{7}$ Los muralistas, por su parte, se inspiraron en las

${ }^{5}$ La traducción es mía.

${ }^{6}$ Cf. Reyes 1992, y Orellana 1991.

${ }^{7}$ En 1921, José Vasconcelos crea para el pintor un Departamento Especial de Dibujo y Enseñanza Artística donde desarrolla su método. Muchos futuros artistas 
técnicas de los obreros que pintaban los muros exteriores de las pulquerías. ${ }^{8}$ Jean Charlot, uno de los pioneros, resume la situación en estos términos:

La cultura popular influyó en el conjunto de nuestra producción en cuanto al ambiente y al contenido social [...] el sujeto del arte popular es el pueblo y era también el sujeto de nuestros murales socialmente conscientes [...]. El arte popular corrigió la tendencia de los pintores de Bellas Artes, al mirar al pueblo desde afuera (Charlot, 38). ${ }^{9}$

La idea de inocultamiento evocada por Monsiváis y de la cual hablamos anteriormente, puede ser útil en el análisis de obras posrevolucionarias. Si nos referimos, por ejemplo, a la pintura mural de Diego Rivera titulada Sueño de una tarde dominical en la Alameda central, ${ }^{10}$ uno de los primeros elementos que viene a la vista es la presencia, en el centro del cuadro, de una elegante mujer vestida de rebozo y falda amarilla (figura 1); su agudo perfil y moreno rostro recuerdan orgullosamente su ascendencia indígena, contrastando con el aire pálido de los elegidos a la caminata dominical. La posición desafiante que ocupa frente a un policía, que le impide el paso al parque, recuerda el nuevo rol de la mujer posrevolucionaria, una mujer que ya no se queda muda. Su ascendencia social nos remite también de manera más amplia al nuevo lugar que quiere ocupar la mayoría de los excluidos en el nuevo escenario. Además de desafiante, dicha mujer se impone también

\footnotetext{
de renombre asistieron a sus clases: Rufino Tamayo, Rodríguez Lozano, Abraham Ángel, Julio Castellanos, Miguel Covarrubias, Antonio Ruiz, Carlos Mérida y el grabador Leopoldo Méndez. Véase la "Introducción" de Alfonso De Nevillate, en Best 1964.

${ }^{8}$ Cf. Rivera 1934.

${ }^{9}$ La traducción es mía.

${ }^{10}$ Para una imagen completa véase: <http://www.diegorivera.com/murals/ala-
} meda.html>. 


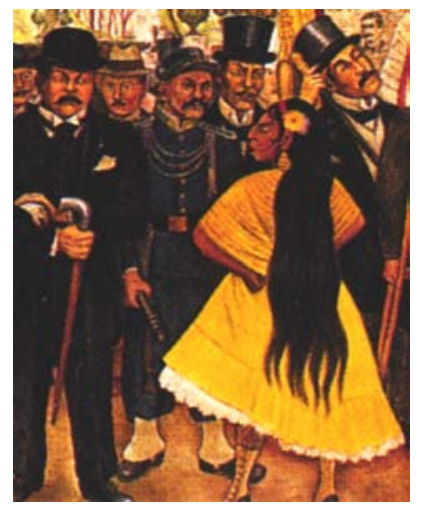

Figura 1. Diego Rivera, Sueño de una tarde dominical en la Alameda central (detalle), Museo Mural Diego Rivera, México, 1947.

por su asumida sensualidad, alzando ligeramente la falda y dejando aparecer sus enaguas y parte de una pierna desnuda.

En el registro literario, una novela como Los de Abajo, de Mariano Azuela, pone también en escena una mujer similar, llamada la Pintada, que se distingue por la fuerza de su carácter y por la audacia con la cual se burla del jefe militar:

- ¿Usted se llama, pues, Demetrio Macías? - preguntó intempestivamente la muchacha que sobre el mostrador estaba meneando las piernas y tocaba con sus zapatos de vaqueta la espalda de Demetrio.

- A la orden - le contestó éste volviendo apenas la cara.

Ella, indiferente, siguió moviendo las piernas descubiertas, haciendo ostentación de sus medias azules [...] (Azuela, 83).

Lejos de dejarse impresionar por este último, la Pintada lo desafía a un duelo visual:

- ¿Con que usté es el famoso Demetrio Macías que tanto lució en Zacatecas? - preguntó la Pintada. Demetrio inclinó la cabeza asintiendo, en tanto que el güero Margarito lanzaba 
una alegre carcajada y decía: “¡Diablo de pinta tan lista!... ¡Ya quieres estrenar general!"

Demetrio sin comprender levantó los ojos hacia ella; se miraron cara a cara como dos perros desconocidos que se olfatean con desconfianza. Demetrio no pudo sostener la mirada furiosamente provocativa de la muchacha y bajó los ojos (Azuela, 83).

Acostarse con Demetrio constituye para la Pintada una nueva victoria al demostrar que nadie puede resistirla. Si el espíritu de libertad, el atrevimiento y la bravura de una mujer como la Pintada intimidan profundamente a los hombres es porque ellos están acostumbrados a mujeres sin carácter. La repentina novedad de hallarse ante una mujer dotada de dicha calidad les deja mudos y desamparados. El hecho de que la Pintada ataque a la nueva novia de Demetrio, Camila - una mujer tradicional, sometida y obediente-, sintetiza de alguna manera la lucha por la liberación de la condición femenina llevada a cabo durante la Revolución.

\section{El realismo crítico}

De manera similar a lo que ocurre durante el Renacimiento en la Europa del Norte, ${ }^{11}$ la época posrevolucionaria mexicana se distingue por la aparición en la creación artística, tanto literaria como plástica, de lo que se podría calificar como realismo crítico. A pesar de que la noción de realismo no aparece como tal

\footnotetext{
${ }^{11}$ Timothy Foote distinguía el renacimiento flamenco del italiano en estos términos: "La oposición entre las obras de los contemporáneos italianos de Brueghel y el magistral éxito nórdico no podía ser más asombroso. Para muchos maestros italianos, el arte se situaba tan lejos de la vida cotidiana como una pintura representativa. Trataban de captar esas escasas formas ideales, que Platón decía a los griegos que habían servido de modelo a los dioses durante la creación; en consecuencia, apreciaban la belleza, la armonía de la composición, las formas matemáticas perfectas de la perspectiva, en detrimento del contenido real de sus pinturas". (Foote 1971, 16; la traducción es mía).
} 
en el arte renacentista, hoy sabemos que en aquel tiempo tanto la literatura como las artes plásticas se dedicaban a la observación y análisis del mundo real. Como recuerda Daniel Berguez, "Rabelais es el mejor ejemplo de ello porque, detrás de las máscaras de la risa popular, del gigantismo y de la revuelta carnavalesca, pone en escena [...] los desafíos sociales y culturales de su tiempo" (Berguez, 11). ${ }^{12}$ Los gigantescos cuadros de Pieter Brueghel, cuyo formato sobrepasa la mayoría de los demás cuadros del siglo XVI, expuestos en el Kunsthistorisches Museum de Viena, revelan escenas populares, muchas veces al aire libre, donde circulan, viven, ríen y lloran decenas de personajes. Hoy en día, numerosos críticos del arte insisten en el valor subversivo de su obra, alegando que el pintor no se limitaba a figurar lo cotidiano, sino que tomaba posición frente al mundo en que vivía. En su análisis detallado del Camino del Calvario (1564), Michael Gibson reconoce, por ejemplo, que, detrás del tema de la crucifixión, se esconde una condena directa en contra de los abusos de poder de la monarquía católica hacia los calvinistas y los libres pensadores del Norte; los soldados tienen características españolas y en la bandera que llevan aparece un águila bicéfala parecida al emblema de los Habsburgo. Para colmo, el tema mismo de la crucifixión evoca las ejecuciones llevadas a cabo en las plazas públicas por los mismos españoles en contra de los nuevos herejes del siglo XVI en Holanda. Brueghel, prosigue Gibson, "había afinado su espíritu crítico durante los fuegos de la Inquisición, de las represiones y de las guerras de religión" (Gibson, 18). ${ }^{13}$

Esta posición crítica se asemeja a la de varios artistas posrevolucionarios mexicanos, quienes desarrollaron un arte combativo en el cual supieron poner en tela de juicio hasta a sus propios mecenas. Rivera recuerda, por ejemplo, lo siguiente:

\footnotetext{
${ }^{12}$ La traducción es mía.

${ }^{13}$ La traducción es mía.
} 


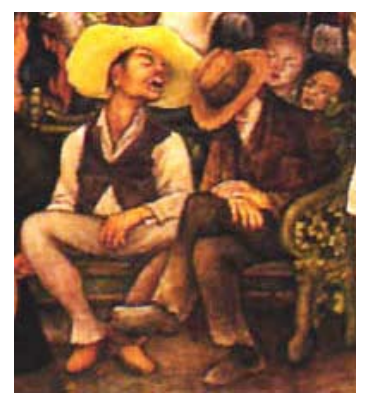

Figura 2. Diego Rivera, Sueño de una tarde dominical en la Alameda central (detalle), Museo Mural Diego Rivera, México, 1947.

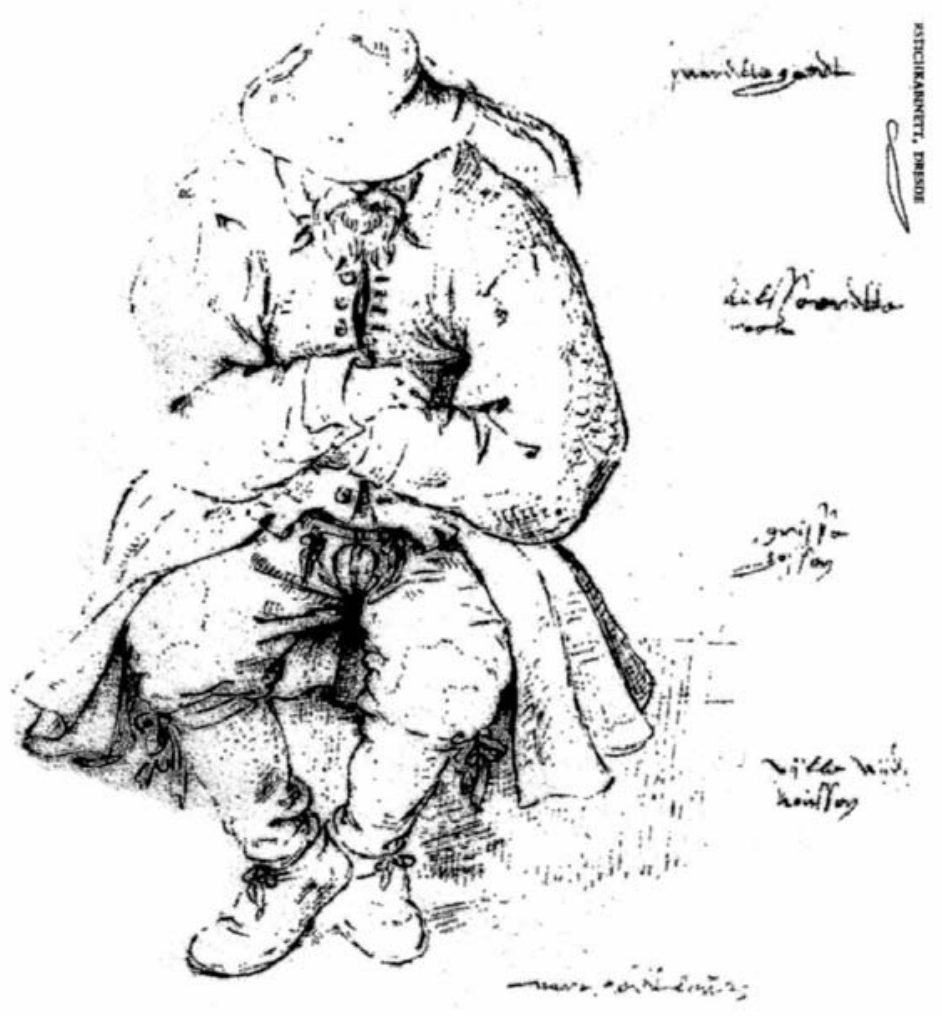

Figura 3. Pieter Brueghel, Campesino sentado y dormido, Kupferstichkabinett, Dresde, 1565. 
Cuando empecé a pintar México de hoy y mañana [una sección de la escalera del Palacio presidencial], mi visión cristalizó por mi reciente experiencia [de los murales destruidos del Rockefeller Center]. Mostré mi desprecio hacia la traición de la Revolución por demagogos egoístas. En contraste con sus promesas, pinté la realidad de México de hoy: huelgas sofocadas, campesinos y trabajadores fusilados o enviados a la colonia penal de las Islas Marías (March, 94). ${ }^{14}$

Unos ejemplos tomados del mural Sueño de una tarde dominical en la Alameda central (1947), al cual nos referimos antes, hablarían en favor de la idea de que Rivera se inspiró en parte en el pintor flamenco. Varios personajes de índole popular que reproduce Rivera, como, por ejemplo, el hombre sentado y dormido (figuras 2 y 3 ), se asemejan mucho a personajes presentes en las obras de Brueghel. Algunas escenas del cuadro podrían remitirnos a las del Camino del Calvario (1564) (figuras 4 y 5): por ejemplo, ambos cuadros retratan a una esposa que interviene como mediadora entre su marido y las

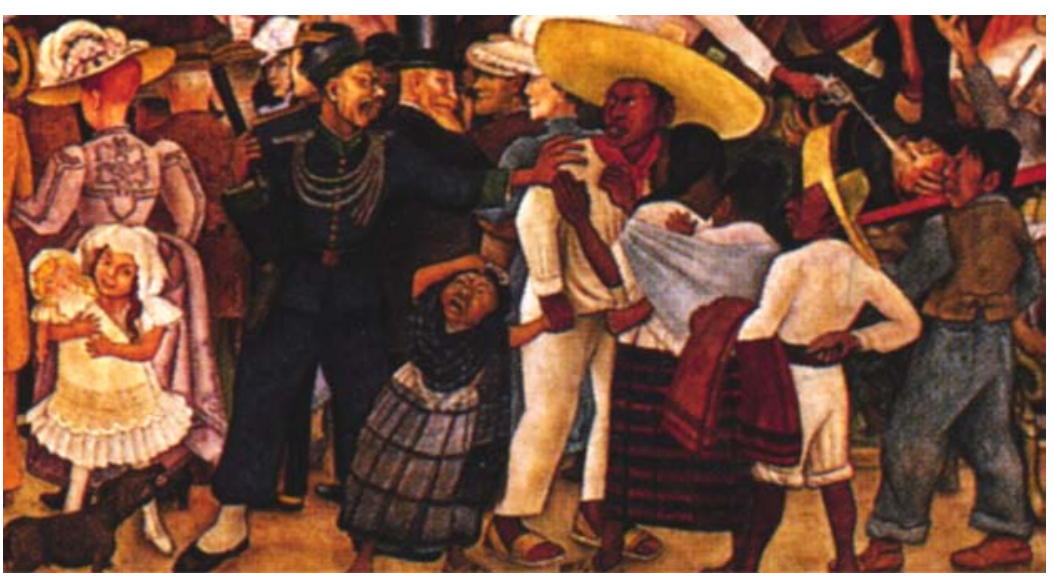

Figura 4. Diego Rivera, Sueño de una tarde dominical en la Alameda central (detalle), Museo Mural Diego Rivera, México, 1947.

${ }^{14}$ Citado por Rodríguez 1997. 


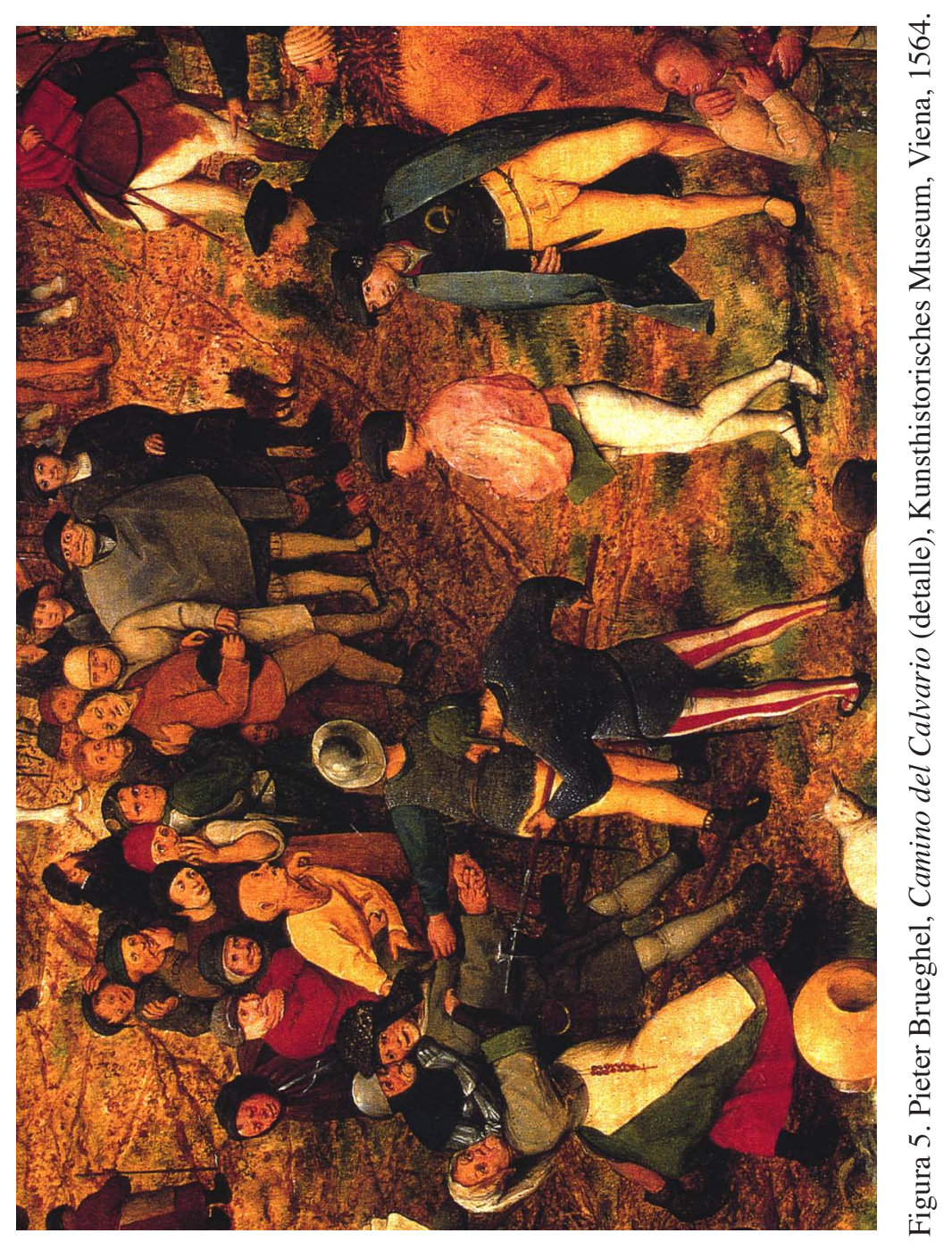


fuerzas del orden; también en ambas pinturas aparece un hombre del pueblo, que mira atentamente la escena, llevando discretamente la mano al cuchillo, como gesto de solidaridad con la pareja. Otra escena es la del joven ladrón, a la izquierda, que trata de apoderarse del pañuelo de un rico, escena irónica que recuerda la obra de Brueghel titulada El misántropo (1568), donde la harapienta vestimenta del pobre parece justificar el delito que está a punto de cometer en contra del hombre rico y poco preocupado por la mala condición de los que lo rodean (figuras 6 y 7). Fácil es comprender el interés de Rivera por un artista de la índole de Brueghel y definido por Elie Faure como "una especie de campesino, cuyo lenguaje inesperado y su extraña y fuerte imaginación han hecho que se considerara por mucho tiempo como un primitivo solamente cómico, quizás

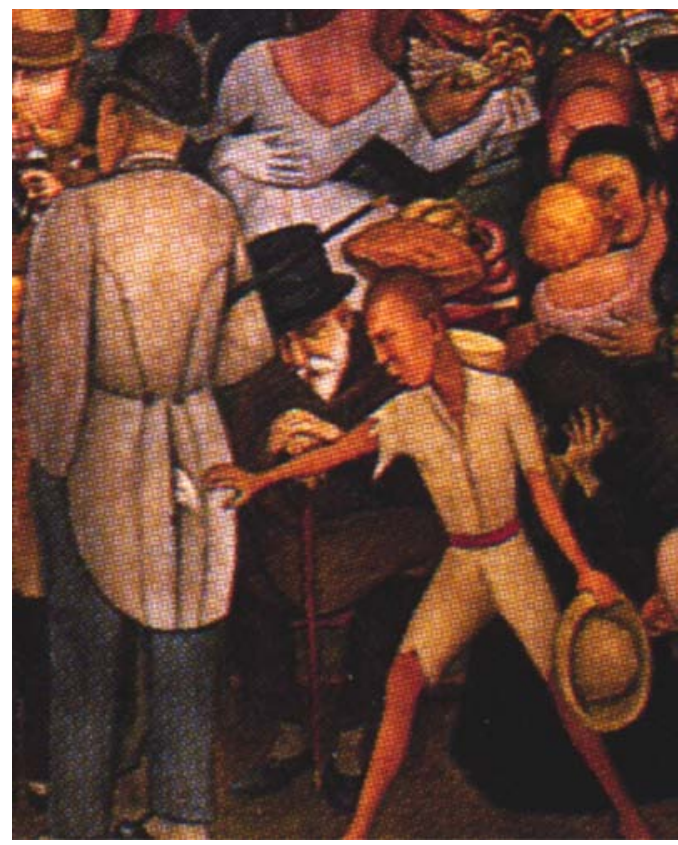

Figura 6. Diego Rivera, Sueño de una tarde dominical en la Alameda central (detalle), Museo Mural Diego Rivera, México, 1947. 
un poco ridículo y cuyo espíritu era libre y audaz, su alma inmensa y radiante" (Faure, 276). ${ }^{15}$ Brueghel era un honesto trabajador y su arte demostraba una profunda preocupación por entender el mundo que lo rodeaba, un esfuerzo constante del artista para reducir al máximo la distancia entre él y los sujetos que pintaba. "Los personajes de Brueghel - recuerda Gibson - no están centrados sobre sí mismos: no están allí para seducir. Al contrario, más bien los solicitan el mundo humano, la naturaleza, las necesidades vitales $\mathrm{y}$, a veces, las relaciones entre los hombres y lo divino" (Gibson, 78). ${ }^{16}$

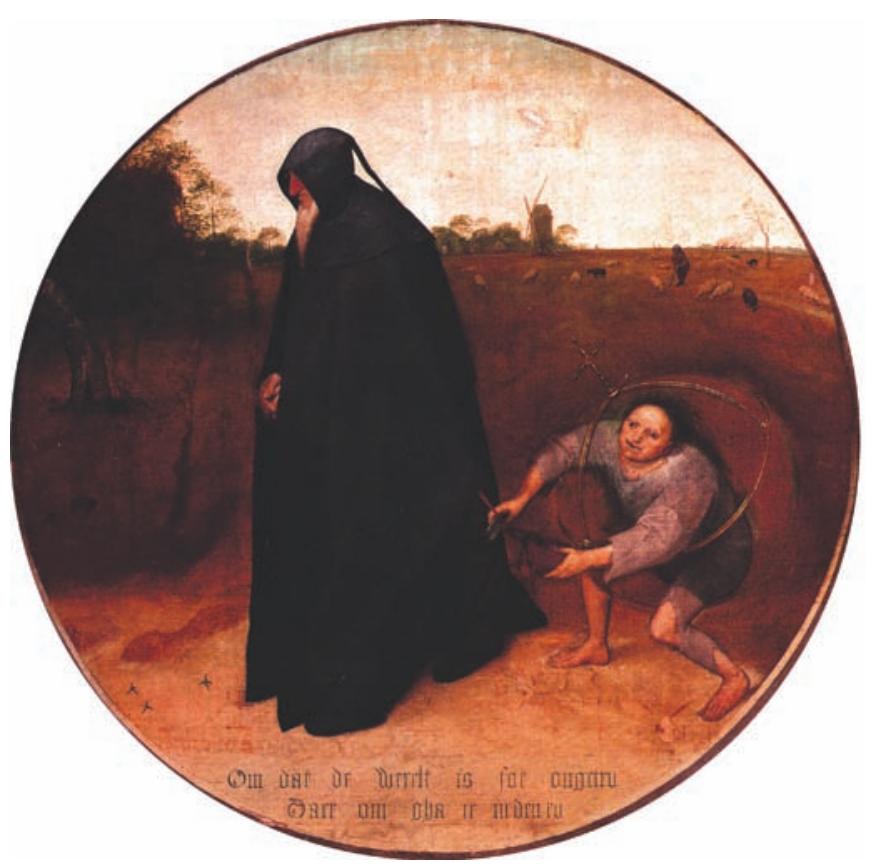

Figura 7. Pieter Brueghel, El misántropo, Capodimonte, Napoli, 1568.

${ }^{15}$ La traducción es mía.

${ }^{16}$ El autor recuerda además que Brueghel concurría con frecuencia a las fiestas populares y a las bodas, haciéndose pasar por un invitado, con el deseo de acercarse a la gente que deseaba retratar (Gibson, 65). Como ocurre con el autorretrato de Rivera en su obra Sueño de una tarde dominical en la Alameda central, muchos han identificado el autorretrato de Brueghel entre los personajes figurados. 


\section{Una naturaleza activa}

Los paisajes que pinta Brueghel, donde el hombre rústico y el campesino están armoniosamente integrados a la naturaleza, podrían evocar algunos que aparecen en ciertas obras posrevolucionarias mexicanas, como los grabados de Leopoldo Méndez (figura 8), las letras de algunos corridos populares - como La Adelita - o las escenas literarias presentes en las novelas de Mariano Azuela y posteriormente en las de Juan Rulfo. El espectador siente el mismo lazo con la tierra, con esos territorios, a la vez tristes y majestuosos, que recorrieron en tiempos de la Revolución los campesinos insurgentes y que los escritores posrevolucionarios se empeñaron en retratar:

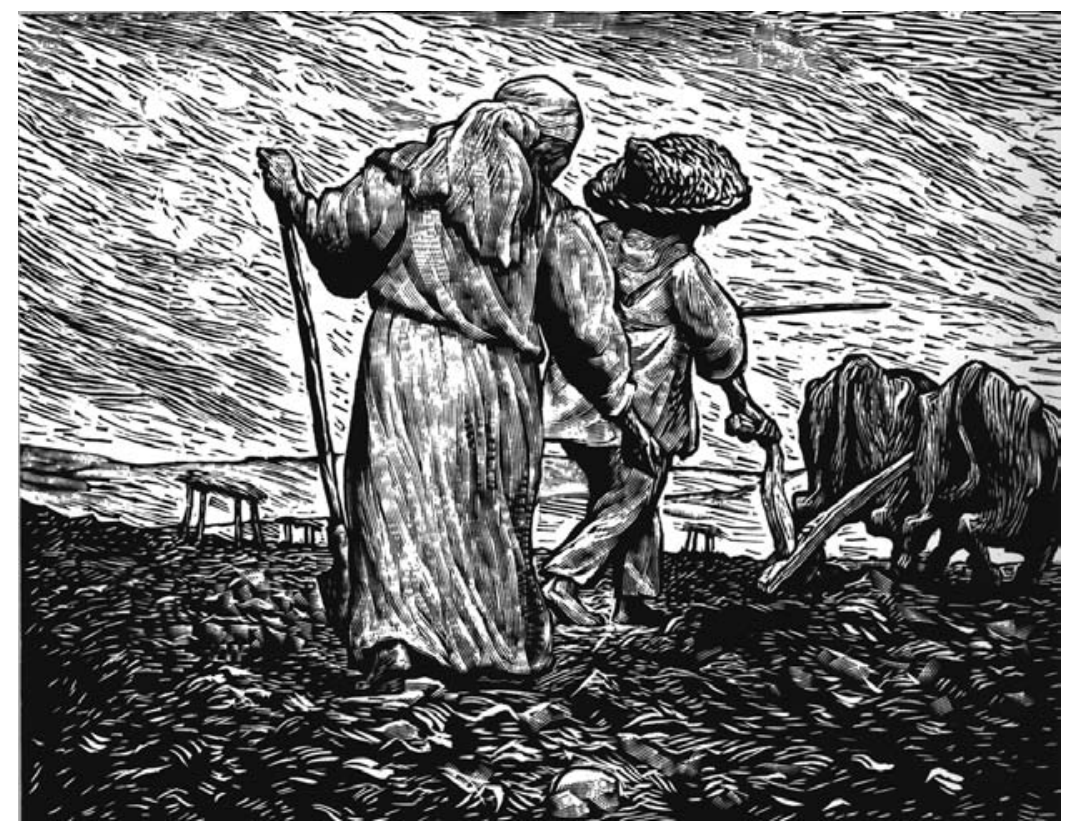

Figura 8. Leopoldo Méndez, La siembra, grabado en linóleo, México, 1948. 
El torbellino de polvo, prolongado a buen trecho a lo largo de la carretera, rompíase bruscamente en masas difusas y violentas, y se destacaban pechos hinchados, crines revueltas, narices trémulas, ojos ovoides, impetuosos, patas abiertas y como encogidas al impulso de la carrera. Los hombres de rostros de bronce y dientes de marfil, ojos flameantes, blandían los rifles o los cruzaban sobre las cabezas de las monturas (Azuela, 110).

Dicho extracto recuerda de alguna manera algunas escenas de El llano en llamas de Juan Rulfo:

Daba gusto mirar aquella larga fila de hombres cruzando el Llano Grande otra vez, como en los tiempos buenos. Como al principio, cuando nos habíamos levantado de la tierra como huizapoles maduros aventados por el viento, para llenar de terror todos los alrededores del Llano. Hubo un tiempo que así fue. Y ahora parecía volver (Rulfo 1973, 72).

En los escritos de Rulfo aparece una naturaleza activa que envuelve a los personajes, una naturaleza de soplo casi humano que, como ocurre con los animados cielos de Brueghel, no sirve de tela de fondo, sino que se une a la narración, como lo vemos en su novela Pedro Páramo:

Al recorrerse las nubes, el sol sacaba luz a las piedras, irisaba todo de colores, se bebía el agua de la tierra, jugaba con el aire de la mañana [...]. Pensaba en ti, Susana. En las lomas verdes. Cuando volábamos papalotes en la época del aire. Oíamos allá abajo el rumor viviente del pueblo mientras estábamos encima de él, arriba de la loma, en tanto se nos iba el hilo de cáñamo arrastrado por el viento (Rulfo 1961, 17-18).

Este procedimiento de fusión entre naturaleza y humanidad proseguirá su camino hasta la literatura más tardía de Carlos Fuentes. Una frase como "Arroyo pensó [...] mirando al cielo, 
que todo tiene un hogar, pero él y las nubes no" (Fuentes, 61), subraya la proximidad entre el hombre y su medio ambiente. Otra frase, como "sus pies enterrados en el polvo sorprendido" (Fuentes, 59) - en alusión al Gringo Viejo-, demuestra cómo el "polvo sorprendido" da cuenta de la misma emoción de sorpresa que sienten los revolucionarios al ver la surrealista aparición del Gringo en el desierto, este "diablo blanco y vengador" con ojos similares al "Dios en las iglesias". La expresión de "polvo sorprendido" denota movimiento y recuerda el aspecto dionisíaco identificado por Aby Warburg en el arte del Renacimiento, donde el viento y los elementos externos otorgan vida y movimiento a los personajes (Michaud, cap. 2, nota 132).

En Gringo Viejo, la naturaleza también se tiñe de los pensamientos de los personajes:

El gringo viejo viajó por el desierto mirando a los tarayes junto a un flaco río. Esas matas sedientas y lujosas atesoran el agua escasa sólo para volverla amarga, salada, inservible para todos (Fuentes, 74).

No se trata, por lo tanto, de una naturaleza pasiva, sino de una que se moldea al desarrollo de la intriga general. Las injusticias, la escasez, la desigualdad, todos temas relacionados con la Revolución, así como la amargura interna del Gringo Viejo, se inscriben hasta en el corazón de las plantas amargas que contempla.

Los insurgentes del Norte, presentes en Gringo Viejo, demuestran odio por la tierra y el deseo de liberarse de ella para siempre:

- Mira la tierra [le dijo Arroyo] - y ella vio un mundo seco, feo, pero hermosamente dramático, fuerte, despojado de generosidad, ajeno a frutos fáciles [...] - No me gusta la tierra, señorita [le dijo el bravo Inocencio Mansalva] [...]. No 
quiero pasarme la vida agachado. Quiero que se destruyan las haciendas y que se deje libre a los campesinos, para que puédamos ir a trabajar donde quiéramos, en la ciudad o en el norte [...].

- Nos ahogábamos en esos pueblos de la provincia [le dijo el coronel Fruto Garcías]. Hasta el aire estaba siempre de luto allí [...] (Fuentes, 63-66).

Al contrario, los personajes del Sur, retratados en las novelas de Rulfo, pelean por una tierra que aman profundamente:

Conforme bajamos, la tierra se hace buena. Sube polvo desde nosotros como si fuera un atajo de mulas lo que bajara por allí; pero nos gusta llenarnos de polvo. Nos gusta. Después de venir durante once horas pisando la dureza del llano, nos sentimos muy a gusto envueltos en aquella cosa que brinca sobre nosotros y sabe a tierra (Rulfo 1973, 18).

Mientras las escenas que elabora Rulfo dan cuenta del alto grado de empatía que une a los insurgentes del Sur con la tierra, el color local desplegado en la novela de Fuentes trasmite el sentimiento de repudio que tiene la gente del Norte por el trabajo de campo.

\section{Nueva lengua, nueva escritura}

En el campo del lenguaje podemos constatar con más evidencia la influencia que ha tenido la cultura popular y callejera sobre el resto del arte. Asistimos en efecto, como ocurre en los carnavales, a una difusión masiva de la lengua popular, de esta "poesía al alcance de todos" o de estas "palabras prohibidas, secretas [...] palabras malditas que sólo pronunciamos cuando no somos dueños de nosotros mismos", de las cuales nos habla Octavio Paz (p. 67). Un análisis detallado de la literatura 
posrevolucionaria permite ver, en efecto, cómo la literatura se esfuerza por dar cuenta del habla común. A las descripciones altamente simbólicas de Azuela en Los de Abajo, por ejemplo, se superpone el lenguaje popular. La mayoría de las frases en estilo directo dan cuenta del habla vernácula ${ }^{17}$ de principios de siglo en México. Los diálogos tienen la tonalidad popular y la espontaneidad que caracteriza el nuevo estilo literario:

Las tres viejas forman animado corro y, hablando en voz muy baja, se ponen a chismorrear con vivísima atención.

- ¡Cierto como haber Dios en los cielos!...

— ¡Ah, pos si yo jui la primera que lo dije: "Marcelina está gorda y está gorda"! Pero naiden me lo quería creer...

- Pos pobre criatura... ;Y pior si va resultando con que es de su tío Nazario!...

- ¡Dios la favorezca!...

- ¡No, qué tío Nazario ni qué ojo de hacha!... ¡Mal ajo para los federales condenados!...

— ¡Bah, pos aistá otra enfelizada más! (Azuela, 35-36).

Dicho lenguaje permite al narrador poner en relieve la diferencia de habla entre clases sociales opuestas. Así ocurre cuando una campesina trata de conversar con el médico Luis Cervantes, supuestamente educado: “¡Oiga!, ¿y quién lo insiñó a curar?... ¿Y pa qué jirvió la agua?... ¿Y los trapos, pa qué los cosió?..." (Azuela, 32). Pero, más que una burla a la ignorancia de la campesina, la superposición de los dos personajes permite al narrador matizar los conceptos de educación e ignorancia. Una conversación entre Luis Cervantes y Demetrio, este héroe popular e icono del pueblo en armas, sirve al narrador para mostrar la otra cara del médico que, si bien había insistido para unir la rebelión local con la revuelta nacional, se reveló como un traidor exclusivamente interesado en el dinero y el poder.

\footnotetext{
${ }^{17}$ Cf., por ejemplo, Gallegos 1950.
} 
- Mire, mi general [dice el médico a Demetrio]; si, como parece, esta bola va a seguir, si la revolución no se acaba, nosotros tenemos ya lo suficiente para irnos a brillarla una temporada fuera del país - Demetrio meneó la cabeza negativamente

- ¿No haría usted eso? ... Pues, ¿a qué nos quedaríamos ya?... ¿Qué causa defenderíamos ahora?

[Demetrio contesta:] —Eso es cosa que yo no puedo explicar, curro; pero siento que no es cosa de hombres... (Azuela, 104-105).

La superposición de dos tipos de discurso opuestos permite mostrar la distancia que separa una parte de la gente educada, que trata de aprovecharse de la situación, con la mayoría del pueblo que ya no se contenta con frases retóricas. Cuando Luis Cervantes decide abandonar las tropas federales para juntarse a los villistas, intentará convencer, por medio de un discurso populista y paternalista, a los insurgentes locales de la importancia de llevar una campaña más extensa:

-La Revolución [dice Luis Cervantes] beneficia al pobre, al ignorante, al que toda su vida ha sido esclavo, a los infieles que ni siquiera saben que si lo son es porque el rico convierte en oro las lágrimas, el sudor y la sangre de los pobres...

- ¡Bah!...., ¿y eso es como a modo de qué?... ¡Cuando ni a mí me cuadran los sermones! - Interrumpió Pancracio(Azuela, 30-31).

Más que juicios de valor, el narrador da vía libre a las conversaciones, dejando surgir las contradicciones, así como los naturales desacuerdos que habitan cualquier proyecto político.

De manera más decisiva que el tema mismo de la Revolución, que no tardó en circunscribir el género literario llamado "Novelas de la Revolución", es la libertad adquirida en la escritura que parece haber influido de manera más profunda en la literatura mexicana del siglo Xx. Lo atestigua de manera clara 
la novela Gringo Viejo, a la cual ya nos hemos referido. Aquí, como en Los de Abajo, aparece de nuevo, pero de manera más enfática aún, un lenguaje tosco y espontáneo: “¿Oye, Gringo idiota, no oíste la orden? ¡Regresa aquí, viejo idiota!” (Fuentes, 59). Con la literatura posrevolucionaria, asistimos a un fenómeno similar al ocurrido en la pintura; en ambos casos se abandona la tradición costumbrista, aplicada a la descripción naturalista de los hábitos, para dirigirse hacia un realismo mucho más crítico (Carballo, 7-32). Bajo la dictadura porfirista, las novelas costumbristas se caracterizaban de manera general por una falsa objetividad de parte del narrador. Muchas veces, más que señalar los desajustes sociales, el narrador manifestaba implícitamente su aceptación de las jerarquías vigentes. Según Martín-Flores, este fenómeno se reflejaba en la adopción de una actitud paternalista y una constante manifestación del narrador que se expresaba en un doble discurso: uno para dar cuenta de los actos y de las palabras de los personajes, el otro para cuestionar su posición ideológica. ${ }^{18}$ Todo lo contrario ocurre en las novelas escritas durante y después de la Revolución, donde el lector asiste al despliegue de una realidad en la cual hasta los más pobres y desheredados adquieren voz. En Gringo Viejo, la abundancia de frases vulgares y de palabras proscritas parece encarnar la voluntad de las clases populares de transgredir las viejas prohibiciones y los tabúes relativos al sexo. Cuando el general Arroyo, una figura que por cierto remite a Demetrio, el héroe local de Los de Abajo, recuerda su pasado, el lector está invitado a compartir el universo de pro-

\footnotetext{
${ }^{18}$ Mario Martín-Flores recuerda, por ejemplo: "En el realismo mexicano [del siglo XIX] la presencia del autor [...] es la de un protagonista que interviene de manera gratuita en cualquier momento: presenta, parafrasea, clarifica, repite, corrige, discute, interrumpe, interpreta, juzga y condena lo que presentan, dicen y hacen los personajes. Esta constante y locuaz posición del autor termina por demostrar a los lectores que lo que leen es ficticio, borrando así todo deseo de complicidad para que puedan identificarse con la realidad o la ficción" (Martín-Flores 1996, 123; la traducción es mía).
} 
hibición, de ocultación y de silencio en el cual creció el general bajo el techo de los hacendados:

Un niño es sólo un testigo. Yo fui el testigo de la hacienda. Porque era el bastardo de los cuartos de servicio, tenía que imaginar lo que ellos ni siquiera volteaban a ver. Crecí oliendo, respirando, oyendo cada rincón de la casa: cada cuarto [...] testigo ausente de cada cópula, apresurada o lánguida, juguetona o aburrida, tierna o fría, de cada defecación, gruesa o aguada, verde o roja, suave o aterronada con elote indigesto, escuché cada pedo, me oyes, cada eructo, cada gargajo caer, cada orín correr, y vi a los guajolotes descarnados cuando les torcían los pescuezos, y los bueyes castrados [...] (Fuentes, 124-125).

Podríamos, ampliando el concepto, referirnos a la idea de "volver inocultable", a la cual nos remite Carlos Monsiváis (p. 149): es decir, si la Revolución permitió inocultar a la mayoría, poniendo en escena su hablar, su modo de ver el mundo y su espontáneo humor, el espíritu crítico que parece animar a los artistas y escritores posrevolucionarios sirvió también para inocultar el juego político y levantar los muros detrás de los cuales se esconden las castas privilegiadas.

Cabe señalar que el fenómeno de "ocultamiento" ya se encontraba en las preocupaciones de los intelectuales de la época, incluyendo los que iban a "contracorriente" de la Escuela de Bellas Artes, como los miembros de la revista Contemporáneos, de los cuales nos habla Jorge Manrique (pp. 233-259). En un artículo titulado "Literatura de la Revolución y literatura revolucionaria", escrito a modo de comentario sobre el universalismo alcanzado por Azuela después de las traducciones al francés y al inglés de Los de Abajo, Ortiz de Montellano afirmaba:

Lo que logró la revolución mexicana con la nueva generación de escritores, puestos desde la infancia a comprobar la amarga 
realidad de esa revolución, fue convencerlos de la existencia de una sensibilidad personal [...]. La realidad profunda [prosigue el autor], oculta hasta entonces, prestó a aquellos adolescentes la experiencia necesaria para madurar con rapidez haciéndoles ver con sus propios ojos el mundo que les rodeaba [...] (Ortiz de Montellano, 80).

Esta misma "realidad profunda oculta hasta entonces" es la que los escritores posrevolucionarios nos hacen descubrir. En la novela Gringo Viejo, por medio de los recuerdos de infancia de Arroyo, se invita al lector a espiar y sondear, desde la perspectiva axiológica de "la gente de abajo", los modos de vivir de los hacendados.

\section{El espejo invertido}

El episodio del espejo, central en la novela Gringo Viejo, sirve de metáfora para expresar la sensación de libertad adquirida por los insurgentes durante la Revolución: “¿Viste cómo se miraron ayer en los espejos? [...] Nunca se habían visto en un espejo de cuerpo entero. No sabían que sus cuerpos eran algo más que un pedazo de su imaginación o un reflejo roto en un río. Ahora lo saben" (Fuentes, 57), le dirá el general Arroyo al Gringo Viejo. La aparición del cuerpo en el espejo es el punto culminante de un largo proceso de inocultamiento que comienza con el escrutinio imaginativo, olfativo, sensitivo, y concluye en la apropiación física y corporal de la imagen reflejada. Arroyo, como personaje, sintetiza el reflejo de esta nueva realidad, encarnando la imagen invertida en el espejo. Su nombre, arroyo, lleva en sí la metáfora del agua y del reflejo. Lo que Arroyo ve, en este río que corre, es la sustitución gradual de "los de arriba" por su propia gente, "los de abajo". Por vez primera, los insurgentes pueden verse de cuerpo entero y tomar posesión de sus cuerpos: 
Nunca habían visto sus cuerpos enteros; yo tenía que darles ese gran regalo, esa fiesta: ahora mírense, muévanse, levanta un brazo, ahora tú, baila una polca, desquítense de todos los años en que vivieron ciegos con sus propios cuerpos, tentando en la oscuridad para encontrar un cuerpo - tu cuerpo - tan extraño y callado y lejano como todos los demás cuerpos que no te permitían tocar o a los que no les permitían tocarte a ti (Fuentes, 119).

El espejo hace posible una forma carnavalesca de cambios de papeles. Pero, más que permanecer en el orden de la figuración temporal, los soldados tienen la convicción de haber operado un cambio de condición permanente. Sus cuerpos ocupan ahora el espacio en el espejo antiguamente reservado a la élite. Se convierten en el nuevo sujeto digno de reflejo:

Mírenlo. Aquí está. Ustedes no pueden mirar a través de Tomás Arroyo. No está hecho de aire, sino de sangre. Es carne, no es vidrio. No es transparente. Es opaco, bola de cabrones hijos de su chingada, es opaco como el muro de la prisión más sólida que ustedes o yo o él jamás penetraremos (Fuentes, 128).

Dicho episodio se trasforma en una verdadera fiesta:

Uno de los soldados de Arroyo adelantó un brazo hacia el espejo.

-Mira, eres tú.

Y el compañero señaló hacia el cuerpo del otro.

-Soy yo.

-Somos nosotros.

Las palabras hicieron la ronda, somos nosotros, somos nosotros, y una guitarra se dejó oír, una voz se unió a otra, los de la caballería entraron también y volvió a haber fiesta y baile y broma en la hacienda de los Mirandas [...] (Fuentes, 45). 
Aunque ficticias, dichas escenas recuerdan algunos episodios que ocurrieron realmente durante la Revolución, como lo vemos en esta escena altamente carnavalesca descrita por Fernando Benítez en 1914, y que Carlos Monsiváis reporta de la siguiente manera:

En la ciudad de México, un grupo de alzados se adueña de la calle, entre las pirámides de la diversión. De pronto se fijan en los grandes espejos extraídos de una mansión y se contemplan divertidos. Se ríen al verse de cuerpo entero y se engalanan con los sombreros de las señoras y señores, con las boas de plumas, con los vestidos de noche y las capas. Su carcajada es un carnaval instantáneo, es el regocijo de quien por fin se juzga a sí mismo de otra manera, alternada drásticamente su circunstancia por la posibilidad de verse de cuerpo entero (Monsiváis, 144).

La escena de Benítez que transcribe Monsiváis tiene indudablemente la huella de la transfiguración carnavalesca. Al travestirse, al vestir los trajes de las damas y de los caballeros, los soldados provocan una carcajada general y operan a su manera una cierta reconstrucción del universo oculto de las casas y de los hábitos aristocráticos. Este universo secreto, proyectado de manera súbita a la calle, se convierte en objeto de burla pública. Los trajes, signos distintivos de las clases sociales, se vacían de su contenido y de potencial autoritario.

\section{La figura del loco}

No podemos ignorar que la tonalidad burlesca presente en las obras que surgen con la Revolución sirve también de contrapeso a una experiencia cotidiana cargada de violencia y terror. En Los de Abajo, por ejemplo, la alegría convive con lo trágico: 
Los soldados caminan por el abrupto peñascal contagiados de la alegría de la mañana. Nadie piensa en la artera bala que puede estarlo esperando más adelante. La gran alegría de la partida estriba cabalmente en lo imprevisto. Y por eso los soldados cantan, ríen y charlan locamente. En su alma rebulle el alma de las viejas tribus nómadas. Nada importa saber adónde van y de dónde vienen; lo necesario es caminar, caminar siempre, no estacionarse jamás; ser dueños del valle, de las planicies, de la sierra y de todo lo que la vista abarca (Azuela, 149).

A la falta de significado de la Revolución, los rebeldes responden con la risa. Es una respuesta instantánea a una revolución que nunca parece acabarse, a un conflicto manchado con sangre que pierde poco a poco su sentido.

La presencia del loco Valderrama, otro personaje que podríamos identificar con el carnaval, ocupa, en la tercera parte de la novela Los de Abajo, un papel decisivo. Pero, más que cómico, dicho personaje da cuenta de la tonalidad trágica que toma la Revolución, como se aprecia en la escena donde Demetrio le pide a Valderrama que le cante El enterrador (Azuela, 140). El hecho de que Demetrio le pida cantar una canción con un título tan macabro aumenta la sensación general de fatalismo que predomina entre los revolucionarios. Si bien se le considera como un loco, Valderrama se revela también como un personaje de alta sensibilidad. Su locura le permite, además, ver con bastante objetividad la situación, e intuir lo que está por venir: "había venido contando las cruces diseminadas por caminos y veredas [...] cruces trazadas con carbón sobre el canto de las peñas. El rastro de los primeros revolucionarios de 1910, asesinados por el gobierno" (Azuela, 142-143). Es más, Valderrama aparece como uno de los únicos que sabe por qué está combatiendo y que cree realmente en la Revolución, como lo deja entender la invocación que profiere al llegar a

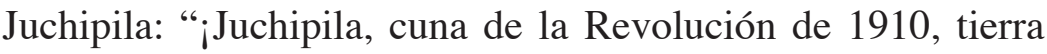
bendita, tierra regada con sangre de mártires, con sangre de 
soñadores...de los únicos buenos!" (Azuela, 142-143). A la vez músico y poeta, este trovador del siglo Xx representa tal vez al último soñador entre las filas de Demetrio, en su mayoría compuestas por exfederales y cuyos motivos ya no tienen nada que ver con los de los primeros insurgentes de 1910. Cuando Valderrama se da cuenta de que están luchando por una causa perdida, será el primero en desertar: "Valderrama, el vagabundo de los caminos reales, que se incorporó a la tropa un día, sin que nadie supiera a punto fijo cuándo ni en dónde, pescó algo de las palabras de Demetrio, y como no hay loco que coma lumbre, ese mismo día desapareció como había llegado" (Azuela, 144-145). En definitiva, la introducción de la figura del loco se convierte en una gran metáfora para simbolizar la absurdidad y el sinsentido de la lucha. La última frase de la novela, donde Demetrio Macías "con los ojos fijos para siempre, sigue apuntando con el cañón de su fusil..." (Azuela, 151), aparece como el punto culminante del sinsentido en el cual ha caído la lucha armada.

\section{La ficción para pensar el mundo}

Si bien los personajes y los paisajes representados en novelas como Los de Abajo y Gringo Viejo encarnan el lenguaje, la espontaneidad y el movimiento que acompañan a la Revolución dan también cuenta de cómo los insurgentes entendían este momento histórico. No cabe duda de que, para los historiadores, la lectura de la novela de la Revolución y la contemplación de obras posrevolucionarias pueden favorecer un entendimiento más amplio de los sucesos históricos. El aspecto tragicómico de la Revolución, que oscila entre el drama y la comedia, la esperanza y el fatalismo, se transmite claramente por la ficción. Más que un simple retrato de la realidad, como se ha visto por mucho tiempo, la novela posrevolucionaria 
permite, por ejemplo, un entendimiento diferente de los problemas a los cuales se enfrentaron los mexicanos en su deseo común de erradicar un sistema viejo para edificar un mundo diverso. Los novelistas posrevolucionarios no cayeron en la trampa de algunos historiadores, quienes, en su voluntad de entender la Revolución mexicana, la interpretaron como un todo homogéneo. El mérito de los escritores consiste posiblemente en haber logrado dejar emerger las contradicciones en el seno mismo de la narración y de los personajes. Considerar las novelas de la Revolución exclusivamente como testimonios históricos equivale a ignorar de entrada la apertura que proponen, es confinarlas en un pasado que buscan sobrepasar, es olvidar que el espíritu crítico de los escritores, este mismo espíritu con el cual critican algunos aspectos de la Revolución, representa un legado innegable del gran proceso social engendrado por esa misma Revolución. La ficción nos invita hacia otra cosa, tiene esa capacidad de aventurarse donde el ensayo no siempre quiere ni puede ir, propone un mundo que distorsiona a su conveniencia para retratar mejor el mundo real. Aun cuando se la nombra realista, la ficción es, en definitiva, siempre "irrealista". Como bien lo dice Roland Barthes: "la literatura es siempre irrealista, pero su irrealismo mismo le permite muchas veces hacer buenas preguntas" (Barthes, 149), ${ }^{19}$ y estas buenas preguntas pasan menos por una ética de verdad histórica, "porque el escritor pierde todo derecho de reapropiación sobre la verdad", que por el espectáculo, cuya dimensión es estética: "lo que gana obviamente - concluye Barthes - es el poder de sacudir el mundo, ofreciéndole el vertiginoso espectáculo de una praxis sin límites" (Barthes, 150). ${ }^{20}$

A la luz de los ejemplos que hemos dado, parece posible reconocer que el espíritu crítico adquirido durante la Revolución dejó una herencia innegable sobre las generaciones pos-

\footnotetext{
${ }^{19}$ La traducción es mía.

${ }^{20}$ La traducción es mía.
} 
teriores, tanto en el arte plástico como en la creación literaria. En esta última, se trata de un savoir-faire que empieza en las novelas de Azuela, que prosigue bajo diversas formas en la escritura de Juan Rulfo y que vuelve a aparecer en las novelas de Carlos Fuentes. Bien podríamos haber hablado de otras novelas tardías, como Los relámpagos de agosto o Los pasos de López de Jorge Ibargüengoitia, donde el tono paródico y la presencia de antihéroes recuerdan tanto a los personajes de Fuentes como a los de Azuela. Ignacio Trejo Fuentes afirmaba, de hecho, que a Ibargüengoitia le gustaba pintar a los primeros gobiernos revolucionarios como una bola de cínicos ladrones, de impulsivos oportunistas, más ambiciosos que realmente triunfantes y siempre sujetos a cambiar su destino de manera inesperada (Trejo Fuentes, 123-132). Decía, por otra parte, que la escritura de Ibargüengoitia se acompañaba siempre con una severa visión ideológica del mundo, y que ésta se hacía posible mediante el juego de la parodia (Trejo Fuentes, 126). No se puede olvidar que, detrás de este espíritu humorístico, $y$ al igual que lo que ocurre en el teatro chico, se esconde una profunda reflexión sobre el mundo. La risa, como bien dice Rabelais en su prólogo al Gargantúa, es una materia seria que no ha de tomarse trivialmente, sino como una invitación para elevarse al corazón del tema (Rabelais, 44). El espíritu burlesco y crítico de Ibargüengoitia puede, sin duda, verse como un legado de los creadores de principios de siglo, tanto profesionales como populares. La indudable herencia dejada por la Revolución Mexicana en las artes, caracterizada como vimos por diversos fenómenos de inocultamiento, es, en suma, prueba de un proceso, consciente o inconsciente, de fidelidad ${ }^{21}$ a lo que podríamos arriesgarnos en llamar "evento artístico de la Revolución mexicana". ${ }^{22}$ Este hecho explicaría por qué los héroes

\footnotetext{
${ }^{21}$ La idea de "fidelidad a un evento" proviene de la filosofía de Alain Badiou (cf. Badiou 1988 y 1993).

${ }^{22}$ Hemos abordado de manera más amplia esta cuestión en nuestra tesis de doctorado (Giasson 2004).
} 
que surgen durante la Revolución vuelven a aparecer a finales del milenio en diversos muros de México, ya no para atacar el porfiriato, sino para abordar problemas actuales, como el nuevo orden mundial y el tratado de libre comercio. Pero esto ya es otro tema. ${ }^{23}$

\section{Bibliografía}

Azuela, Mariano, Los de Abajo, México, FCE, 1998.

Badiou, Alain, L'éthique, Paris, Hatier, 1993.

—, L'être et l'événement, Paris, Seuil, 1988.

BAKhtine, Mikhaïl, L'œuvre de François Rabelais et la culture populaire au Moyen Âge et sous la Renaissance, Paris, Gallimard, 1982.

BARTHES, Roland, Essais critiques, Paris, Seuil, 1971 (1964).

Bergson, Henri, Le rire, Vendôme, Quadrige-PUF, 1985 (1940).

Berguez, Daniel, Littérature et peinture, Paris, Armand Colin, 2004.

Best Maugard, Adolfo, Método de dibujo, México, Editorial Viñeta, 1964.

CARballo, Emmanuel, "Del costumbrismo al realismo crítico", Espiral, núm. 91, 1964, 7-32.

Charlot, Jean, The Mexican Mural Renaissance, New Haven and London, Yale University Press, 1963.

FAure, Élie, Histoire de l'art. L'art renaissant, Paris, Denoël, 1988. Foote, Timothy, Brueghel et son temps, Verona, Time-Life, 1971. Fuentes, Carlos, Gringo Viejo, México, FCE, 1992 (1985).

Gallegos, Abran, El lenguaje popular en las novelas de Mariano Azuela, tesis de maestría en artes en Español, México, UNAM, 1950.

Giasson, Patrice, "L'esprit d'une renaissance. Dialogue entre les Arts et les Lettres dans le Mexique post-révolutionnaire", Studi

${ }^{23}$ Véase, por ejemplo, el trabajo del muralista Ariosto Otero en la exposición electrónica "La Cabalgada de los Muros": <http://nuevomundo.revues.org/ optika/7/>. 
Latinoamericani, Udine, Centro Internazionale Alti Studi Latinoamericani, núm. 1, 2005, 163-183.

Giasson, Patrice L'Événement artistique de la Révolution mexicaine, Thèse de doctorat, Département de Littérature comparée, Université de Montréal, Montréal, 2004.

Gibson, Michael, Le Portement de croix, Paris, Noêsis, 1996.

GiménEZ, Catalina H. de, Así cantaban la revolución, México, Consejo Nacional para la Cultura y las Artes, 1991.

MAnRique, Jorge, "La Contracorriente", en Jorge Manrique, Una visión del arte y de la historia, México, UnAM, 2001, pp. 233259.

MArch, Gladys, y Diego RiverA, My Life, My Art. An Autobiography, New York, Dover, 1994.

MARIA y CAMPOS, Armando de, El teatro de género chico en la Revolución Mexicana, México, Consejo Nacional para la Cultura y las Artes, Cien de México, 1996 (1956).

MARTín-Flores, Mario, "Nineteenth-century prose fiction", en Mexican Literature, Austin, University of Texas Press, 1996.

MendozA, Vicente, El corrido de la Revolución Mexicana, México, UNAM, 1990 (1956).

Michaud, Philippe-Alain, Aby Warburg et l'image en mouvement, Paris, Macula, 1998.

Monsiváis, Carlos, "La cultura popular", en El Siglo de la Revolución Mexicana, México, Instituto Nacional de Estudios Históricos de la Revolución Mexicana, tomo II, 2000, pp. 143-160.

Orellana, Margarita de, La mirada circular, México, Artes de México, 1991.

Ortiz de Montellano, Bernardo, "Literatura de la Revolución y literatura revolucionaria", Contemporáneos, México, núm. 23, 1930, pp. 77-81.

PANOFSKY, Erwin, La Renaissance et ses avant-courriers dans l'art d'Occident, Paris, Flammarion, 1993 (1960).

PAz, Octavio, El laberinto de la soledad, México, FCE, 1984 (1959).

RABELAIS, François, La vie très horrifique du grand Gargantua, Paris, Garnier Flammarion, 1968.

Reyes, Aurelio de los, Con Villa en México, México, unam, 1992. 
Rivera, Diego, "Introduction", Portrait of America by Diego Rivera, New York, Covici Friede Publishers, 1934.

-, "La pintura mexicana", Excélsior, México, 18 de marzo de 1942, año XXVI, tomo II, sección II, pp. I-IV.

RODRÍGUEZ MORTELlARO, Itzel, "La nación mexicana en los murales del Palacio Nacional (1929-1935)", en Los murales del Palacio nacional, México, Américo Arte Editores e Instituto Nacional de Bellas Artes, 1997, pp. 55-132.

Rulfo, Juan, El llano en llamas, FCE, 1973 (1953).

-, Pedro Páramo, México, FCE, tercera edición, 1961 (1955).

TREJo Fuentes, Ignacio, "Jorge Ibargüengoitia, el gran parodista", en Ensayos sobre la novela mexicana, México, UNAM, 1987, pp. 123-132. 